\title{
Correction to: Dynamics and Characterization of Aeolian Dust Deposition from a Burned Shrubland at Chubut Coastal Patagonia in Argentina
}

\author{
Augusto César Crespi-Abril ${ }^{1,2}(-) \cdot$ Gaspar Soria $^{1,2}$. Elena Barbieri ${ }^{1,2}$. Flavio Paparazzo ${ }^{1,2} \cdot$ Antonella De Cian $^{1,2}$. \\ Rodrigo J. Gonçalves ${ }^{1,2}$
}

(c) King Abdulaziz University and Springer Nature Switzerland AG 2022

\section{Correction to: Earth Systems and Environment https://doi.org/10.1007/s41748-021-00272-z}

Unfortunately, in the original publication one of the coauthor name is published wrongly as Rrodrigo Gonçalves, it should be Rodrigo J. Gonçalves.

We regret the inconvenience caused.

The original article has been updated.

1 Laboratorio de Oceanografía Biológica (LOBio), Centro para el Estudio de los Sistemas Marinos (CESIMARCENPAT-CONICET), Boulevard Brown 2915, 9120 Puerto Madryn, Chubut, Argentina

2 Instituto Patagónico del Mar (IPaM), Universidad Nacional de la Patagonia San Juan Bosco, Boulevard Brown 2930, 9120 Puerto Madryn, Chubut, Argentina 